\title{
Reconstrução com implante metálico personalizado de artrodese após ressecções de tumor ósseo do rádio distal. Experiência em um único centro*
}

\section{Reconstruction with a Custom-made Prosthetic Wrist Arthrodesis after Bone Tumour Resections of the Distal Radius. Single Centre Experience}
Bartlomiej Szostakowski ${ }^{10}$
Eric Staals ${ }^{1}{ }^{10}$ Lyris Onwordi ${ }^{1}$
Robin Pollock ${ }^{1 \odot}$ John A. Skinner ${ }^{1 \odot}$
${ }^{1}$ Unidade conjunta de Reconstrução e Sarcoma, Royal National
Orthopaedic Hospital NHS Trust, Brockley Hill, Stanmore, Middlesex,
HA7, Reino Unido
Rev Bras Ortop 2021;56(2):224-229.

\begin{abstract}
Endereço para correspondência Bartlomiej Szostakowski, Reconstrução Conjunta e Unidade sarcoma, Royal National Orthopaedic Hospital NHS Trust | Brockley Hill Stanmore | Middlesex I HA7 4LP, Reino Unido (e-mail: bartek.szostakowski@gmail.com).
\end{abstract}

\begin{abstract}
Resumo
Palavras-chave

- sarcoma

- tumores de células gigantes

- rádio distal

- punho

- artrodese

- prótese

Objetivo $\mathrm{O}$ presente estudo teve como objetivo analisar os resultados clínicos, radiológicos e funcionais da reconstrução do rádio distal após a ressecção do tumor com implante metálico personalizado de artrodese e compará-los com outros tipos de reconstrução do rádio distal, conforme apresentado na literatura.

Pelo que conhecemos, este é o primeiro artigo descrevendo esse tipo particular de implante e funcionalidade no paciente.

Métodos Os desfechos funcionais de reconstrução do rádio distal foram avaliados em uma série de 4 pacientes. Três dos pacientes tiveram ressecção de tumores de células gigantes (TCGs), sendo um paciente com ressecção de osteossarcoma.

Resultados Não houve complicações relacionadas ao implante, como infecção, não sindicalidade ou afrouxamento. Dois pacientes tiveram que passar por uma nova cirurgia para a protusão da prótese metálica. A função geral foi boa de acordo com as pontuações da Musculoskeletal Tumor Society (MSTS) e Disabilities of the Arm, Shoulder, and Hand (DASH).

Conclusão $\mathrm{O}$ estudo mostra que o implante metálico personalizado de artrodese se beneficia do fato de que pode ser usado como opção de salvamento quando outros tratamentos falharam, ou pode ser usado como opção primária nos casos em que há estoque ósseo limitado após a ressecção do tumor do rádio distal.
\end{abstract}

\footnotetext{
Trabalho desenvolvido na Joint Reconstruction and Sarcoma Unit, Royal National Orthopaedic Hospital NHS Trust, Brockley Hill, Stanmore, Middlesex, HA7.
}

recebido

27 de Abril de 2020

aceito

17 de Setembro de 2020

Publicado online

Março 22, 2021
DOI https://doi.org/ $10.1055 / \mathrm{s}-0040-1721366$ ISSN 0102-3616.
(C) 2021. Sociedade Brasileira de Ortopedia e Traumatologia. All rights reserved.

This is an open access article published by Thieme under the terms of the Creative Commons Attribution-NonDerivative-NonCommercial-License, permitting copying and reproduction so long as the original work is given appropriate credit. Contents may not be used for commercial purposes, or adapted, remixed, transformed or built upon. (https://creativecommons.org/ licenses/by-nc-nd/4.0/)

Thieme Revinter Publicações Ltda., Rua do Matoso 170, Rio de Janeiro, RJ, CEP 20270-135, Brazil 


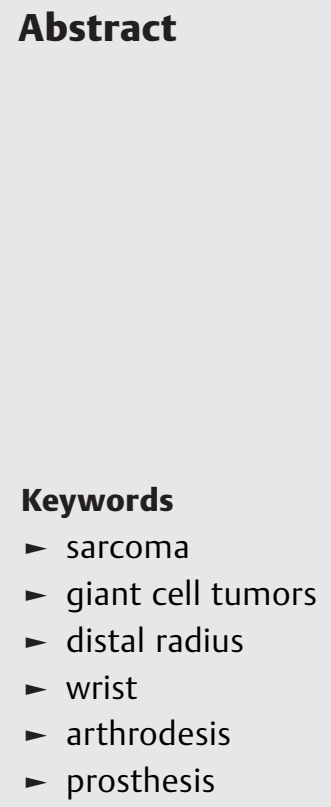

Objective The present study aimed at analyzing the clinical, radiological and functional results of the reconstruction of the distal radius after tumor resection with a custom-made metal arthrodesis implant and compare them with other types of distal radius reconstruction, as presented in the literature.

To our best knowledge, this is the first article describing this particular type of implant and patient functionality.

Methods Functional outcomes of reconstruction of the distal radius were assessed in a series of 4 patients. Three of the patients having had resection of giant cell tumors (GCTs), one patient having had resection of osteosarcoma.

Results There were no major implant-related complications like infection, nonunion or loosening. Two patients had to undergo further surgery for protruding metalwork. Overall function was good according to the Musculoskeletal Tumor Society MSTS and Disabilities of the Arm, Shoulder, and Hand (DASH) scores.

Conclusion The present study shows that custom-made metal arthrodesis implant benefits from the fact that it can be used as a salvage option when other treatments have failed, or it can be used as a primary option in cases in which there is limited bone stock after distal radius tumor resection.

\section{Introdução}

A reconstrução do rádio distal após uma ressecção segmental para um tumor ósseo é muitas vezes desafiadora. As ressecções do bloco são geralmente indicadas para tumores ósseos malignos primários e, ocasionalmente, para tumores ósseos benignos avançados ou recorrentes. A dificuldade em reconstruir o rádio distal deve-se à complexa anatomia da articulação do punho, à proximidade de importantes estruturas neurovasculares e à escassa cobertura de tecido mole local. Como esses pacientes são frequentemente jovens e ativos, uma reconstrução funcional, estável e durável é necessária.

Muitas técnicas foram aplicadas para reconstruir o rádio distal após a ressecção do tumor. A artrodese do punho ou a reconstrução articular podem ser alcançadas usando aloenxertos maciços, autoenxertos vascularizados ou não vascularizados, transposição ulnar e implantes endoprotéticos. A maioria dos relatórios sobre a reconstrução do rádio distal após a ressecção do tumor é de estudos de caso único ou pequenas séries, devido à raridade dessa indicação. ${ }^{1}$

Os autores do presente estudo descrevem uma única experiência de instituição na reconstrução do rádio distal após a ressecção do tumor com implante metálico de artrodese feito sob medida. 0 objetivo do presente estudo foi analisar os resultados clínicos, radiológicos e funcionais e compará-los com outros tipos de reconstrução do rádio distal, conforme apresentado na literatura.

\section{Materiais e Métodos}

Foi realizada uma revisão retrospectiva de 4 reconstruções consecutivas do rádio distal com implante metálico de artrodese personalizado. Todas as operações foram realizadas na instituição dos autores no período de 2009 a 2013. Os dados clínicos foram obtidos a partir das notas: foram avaliadas radiografias simples e os pacientes foram contatados pessoalmente para a avaliação funcional. Foram coletados dados relativos aos pacientes (idade, gênero, dominância da mão), características do tumor (diagnóstico, estágio, margens), cirurgia (profilaxia antibiótica, abordagem cirúrgica, duração da ressecção, reconstrução de tecidos moles), desfecho oncológico e função. Os resultados funcionais foram analisados de acordo com os sistemas de pontuação da Musculoskeletal Tumor Society (MSTS) e Disabilities of the Arm, Shoulder, and Hand (DASH). A avaliação radiográfica incluiu posição e fixação do implante, alinhamento articular e alterações degenerativas nas articulações próximas.

\section{Prótese}

O implante utilizado para a reconstrução do rádio distal foi, em todos os casos, uma endoprótese de titânio personalizada CAD-CAM (Stanmore Implants Worldwide, Elstree, Reino Unido). O desenho do implante foi baseado em filmes de medição pré-operatória e reconstruções de tomografia 3D. Todos os implantes tinham uma haste lisa para fixação de cimento no rádio residual, duas placas de ponte para fixação de parafusos nos ossos do metacarpo, e um colar de hidroxiapatita na extremidade proximal e distal para melhorar a osteointegração e a fixação a longo prazo.

\section{Cirurgia}

A cirurgia foi realizada após profilaxia antibiótica padrão de acordo com o protocolo institucional, (1,5 g de cefuroxime por indução, seguida de $750 \mathrm{mg}$ de doses pós-operatórias a cada 8 horas para completar $24 \mathrm{~h}$ ). 0 acesso cirúrgico foi obtido por meio de uma abordagem dorsal em todos os casos com incisão mais longa, permitindo a fixação metacarpal de placas de ponte. 
O nível de ressecção do rádio distal foi baseado em filmes de medição pré-operatória e varreduras. A endoprótese metálica personalizada foi usada para reconstrução, criando uma fusão da articulação do punho. A fixação proximal no eixo radial residual foi obtida com cimento polimetilmetato (PMMA). Distalmente, a cartilagem articular foi removida dos ossos escafoides e lunate, para melhorar o contato ósseo para implantar contato na primeira linha de carpos. Em seguida, o implante foi fixado com parafusos e duas placas de ponte nos ossos metacarpo. 0 posicionamento e o desenho das placas de ponte foram feitos individualmente, levando em consideração a contratura de tecido mole após cirurgia prévia, estudos de imaginação pré-operatória e anatomia do paciente. A centralização do punho foi primordial para a funcionalidade pós-operatória; portanto, o posicionamento das placas de ponte em diferentes metacarpos. 0 membro operado foi então imobilizado em um molde acima do cotovelo por 4 semanas, seguido por uma tala de pulso por mais 4 semanas.

\section{Resultados}

\section{Características do paciente}

Dois homens e duas mulheres, com idade média de 42,5 anos (faixa de 22 a 55 anos). Todos os quatro casos foram discutidos na reunião da equipe multidisciplinar do Sarcoma, onde foram analisados os resultados disponíveis de imagem e biópsia, e foi estabelecido um caminho de tratamento.

\section{Caso 1}

Uma paciente do sexo feminino dominante à direita, de 42 anos, já havia sido submetida a uma ressecção e reconstrução do rádio distal direito com enxerto fibular não vascularizado para um tumor de células gigantes (TCG) primário do osso, 12 meses antes. Ela então apresentou uma extensa doença recorrente para a qual foi submetida à excisão. Isso incluiu a ressecção do enxerto fibular. 0 punho foi reconstruído com artrodese com implante endoprotético feito sob medida, e a paciente recebeu 56Gy de radioterapia pós-operatória para evitar maior recidiva local (-Fig. $\mathbf{1}$ ).

\section{Caso 2}

Uma paciente feminina dominante à direita de 22 anos apresentou-se com um osteossarcoma osteoblástico localizado de alto grau do rádio distal esquerdo, com uma grande extensão de tecido mole. Ela foi submetida a quimioterapia neoadjuvante de acordo com os protocolos de tratamento oncológico padrão (EURAMOS-1). A ressecção do rádio distal foi associada à ressecção en-bloc da ulna distal para obter amplas margens de ressecção cirúrgica (-Fig. 2).

\section{Caso 3}

Um paciente do sexo masculino dominante à direita, de 54 anos, apresentou-se com um TCG primário do osso no rádio distal esquerdo, para o qual foi submetido a ressecção e reconstrução protética com uma artrodese feita sob medida. Neste caso, não foram aplicados tratamentos adjuvantes (-Fig. 3).
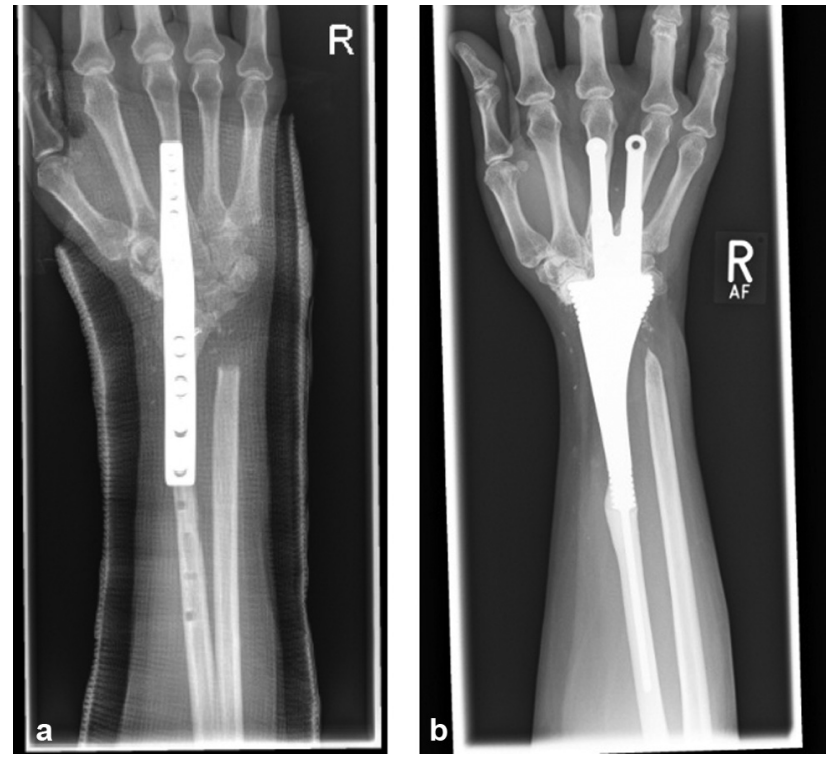

Fig. 1 (a) Enxerto fibular não vascularizado. Devido à recorrência local, o enxerto de fíbula foi posteriormente extirpado e uma prótese personalizada de artrodese de punho foi implantada (b).

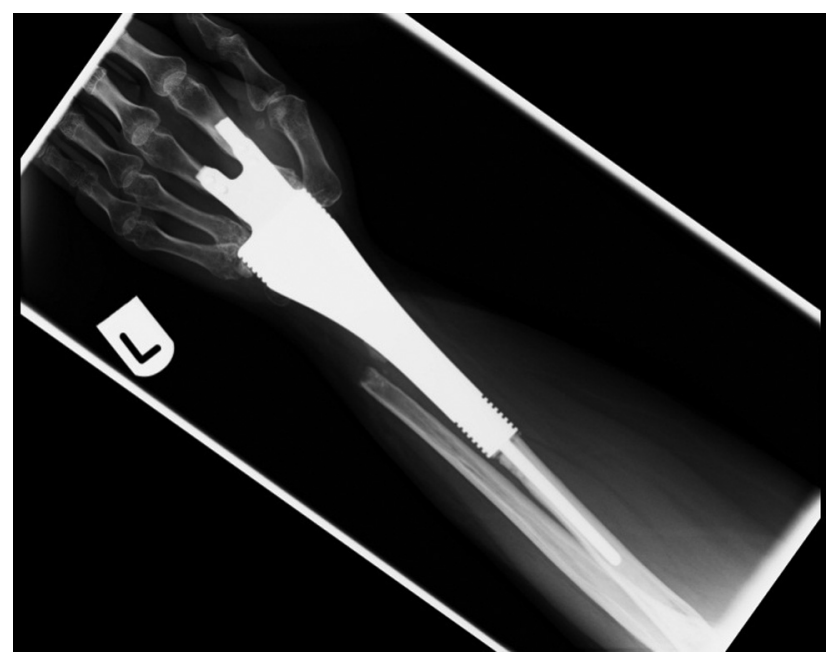

Fig. 2 Raio-x de seguimento do implante personalizado de artrodese do punho mostrando placas de ponte metacarpo aparadas.

\section{Caso 4}

Um paciente do sexo masculino dominante à direita de 50 anos foi submetido a uma ressecção e reconstrução do rádio distal esquerdo com um autoenxerto fibular não vascularizado para um TCG primário do osso. Após 6 meses, o enxerto fibular foi infectado, e o paciente passou por uma revisão em primeiro estágio com a remoção do enxerto e implantação de um espaçador de cimento carregado com antibióticos. Após 6 semanas de tratamento antibiótico intravenoso, todos os parâmetros de infecção voltaram ao normal, e o paciente passou por uma revisão de segundo estágio com uma artrodese protética do rádio distal feita sob medida ( - Fig. 4).

\section{Resultado}

O seguimento médio após artrodese com implante endoprotético feito sob medida foi de 50 meses (intervalo de 22 a 70 


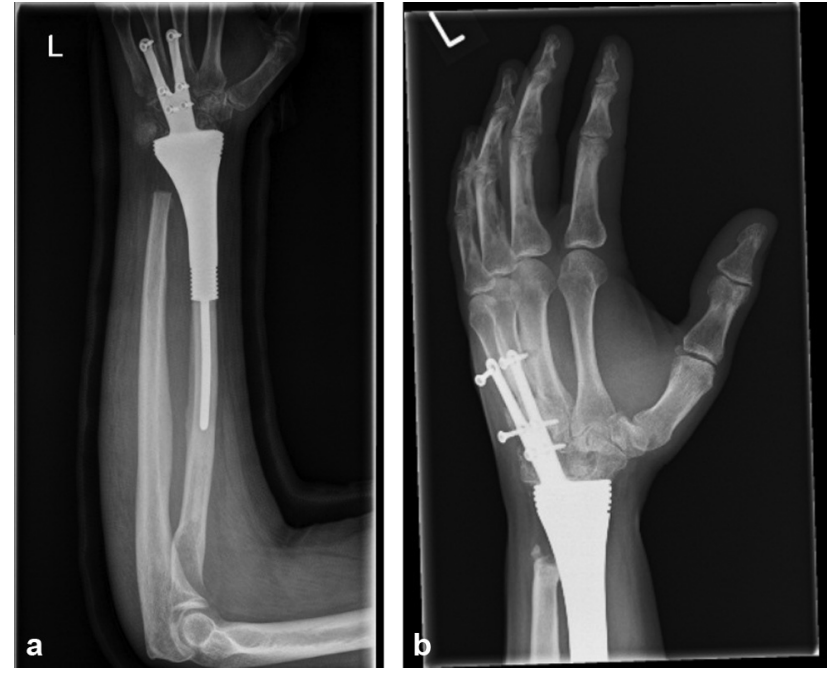

Fig. 3 (a) Raio-x pós-operatório do implante personalizado de artrodese do punho. (b) Raio-x de seguimento mostrando parafusos em protrusão.

meses). Não houve recorrências durante o período de seguimento. Não houve complicações perioperatórias. As feridas cicatrizaram bem em todos os casos e não havia sinais de infecção. Todos os implantes fundidos completamente com a primeira linha carpal, todo o punho mostrou bom alinhamento, e não havia sinais radiológicos de afrouxamento da haste no último seguimento. Nenhum paciente reclamou de dor relacionada ao implante. No entanto, em dois casos os parafusos recuaram das placas de ponte ao nível dos ossos metacarpo, causando problemas de pele no lado dorsal da mão. Ambos os pacientes foram submetidos à remoção dos parafusos em um dia de procedimento sem sacrificar a funcionalidade do implante ou a interrupção da artrodese entre implante e ossos de carpo. Em um desses casos, também uma placa em protrusão foi parcialmente removida ao mesmo tempo. Os resultados funcionais dos quatro casos, de acordo com os escores do MSTS e DASH, são apresentados na - Tabela 1.

\section{Discussão}

No presente estudo, foram avaliados os desfechos funcionais de reconstrução do rádio distal em 4 pacientes utilizando prótese personalizada, três dos pacientes tendo tido ressecção de TCGs, e um paciente tendo tido ressecção de osteossarcoma. Tumor celular gigante do osso é um tumor ósseo benigno e localmente agressivo. A história natural do TCG é a destruição óssea progressiva que leva a deformidade e incapacidade articulares. O rádio distal é um dos locais mais comuns de TCG, após o fêmur distal, a tíbia proximal e o fêmur proximal. ${ }^{2}$ Osteossarcoma é o tumor ósseo maligno primário mais comum, mas $<1 \%$ surgem no rádio distal. ${ }^{3,4}$

Tumores de células gigantes de Campanacci grau II e III, osteosarcomas e outros tumores que causam afinamento ou penetração do córtex são particularmente desafiadores de tratar.

A ressecção do rádio distal é uma rara indicação cirúrgica. Considera-se o tratamento de escolha para tumores ósseos agressivos com grande destruição óssea e apresentação

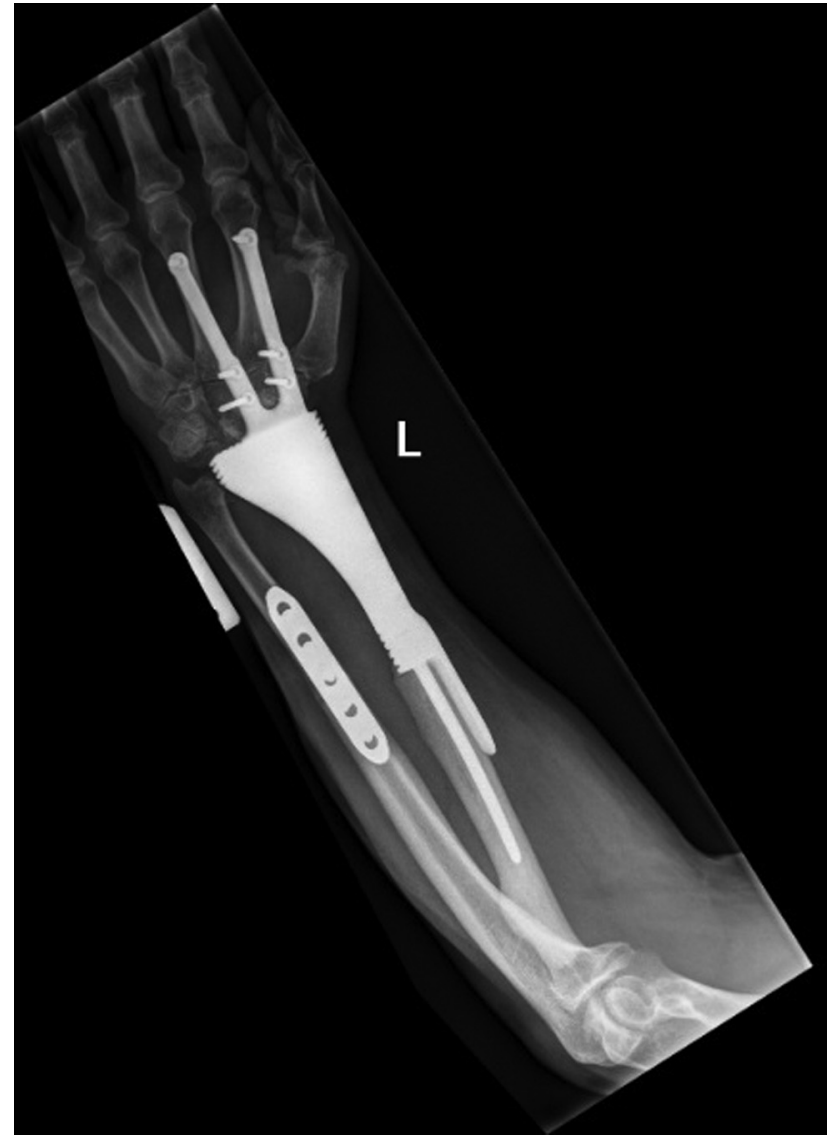

Fig. 4 Raio-x pós-operatório do implante personalizado de artrodese do punho.

avançada. A excisão ampla nesses casos cria um defeito na extremidade distal do rádio.

Inúmeros procedimentos visando a reconstrução do defeito ósseo segmental e a funcionalidade do membro superior estão descritos na literatura. Estes incluem: autoenxertos fibulares vascularizados e não vascularizados, aloenxertos segmentais maciços, transposição ulnar e megaprótese da articulação do punho feita sob medida. ${ }^{5-8}$ A literatura limitada sobre a reconstrução do rádio distal não fornece consenso em relação às melhores técnicas de reconstrução cirúrgica. A escolha da técnica de reconstrução é geralmente baseada na extensão do tumor e nas características do paciente (idade, demanda funcional), mas também na disponibilidade de recursos reconstrutivos. Alusões maciças requerem uma organização de banco de ossos. 0 método de escolha da reconstrução tende geralmente a ser o uso de enxertos fibulares, vascularizados ou não vascularizados. As vantagens dos enxertos fibulares incluem sua semelhança anatômica com o rádio distal e, portanto, sua capacidade potencial de permitir a preservação do movimento na articulação do punho. Embora estudos tenham mostrado resultados promissores, enxertos fibulares vascularizados requerem perícia microcirúrgica. Uma das maiores séries de reconstruções vascularizadas de enxerto fibular após a ressecção do tumor em procedimentos de salvamento de membros documentou um risco considerável de complicações, incluindo taxas de revisão ou necessidade de cirurgia adicional em 35\%. ${ }^{9}$ Estudos também mostraram faixa limitada de 
Tabela 1 Os resultados funcionais dos quatro casos, de acordo com os escores do MSTS e DASH

\begin{tabular}{|l|l|l|l|l|l|l|l|l|}
\hline $\mathrm{Nr}$ & Sexo & Idade (anos) & Diagnóstico & Acompanhamento (meses) & Lado & Domínio & MSTS (\%) & DASH \\
\hline 1 & F & 42 & TCG & 70 & Direita & Direita & 57 & 63 \\
\hline 2 & F & 22 & OS & 54 & Esquerda & Direita & 57 & 37 \\
\hline 3 & M & 54 & TCG & 56 & Esquerda & Direita & 77 & 46 \\
\hline 4 & M & 50 & TCG & 22 & Esquerda & Direita & 73 & 20 \\
\hline
\end{tabular}

Abreviações: DASH, Disabilities of the Arm, Shoulder, and Hand; F, feminino; M, masculino; MSTS, Musculoskeletal Tumor Society; OS, osteosarcoma; TCG, tumor de células gigantes.

movimento no punho e mudanças degenerativas aceleradas na articulação fibular-carpal em algumas séries. ${ }^{10-12}$ Aloenxertos osteoarticulares representam uma opção atraente, com estudos mostrando bons resultados. Implantes impressos em 3D feitos sob medida ainda permanecem uma solução relativamente cara. $\mathrm{O}$ tipo de reconstrução pode manter o movimento articular ou criar uma fusão estável da articulação do punho. A artrodese do punho pode ser subclassificada em artrodese total (ponte do antebraço aos ossos metacarpo) ou artrodese parcial (fixação do rádio distal à primeira linha de carpo). A fusão total do punho tem sido considerada como o conceito de tratamento mais previsível, com a crença de que resulta apenas em incapacidade funcional limitada. ${ }^{13}$ Embora o resultado funcional seja aceitável para a maioria dos pacientes, alguma adaptação é necessária, pois certas atividades como cuidados pessoais e manipulação da mão em espaços apertados são difíceis. ${ }^{14}$ Não está claro até que ponto algum movimento do punho é útil ou necessário. Na maioria das tabelas de comprometimento, há uma relação linear entre o movimento do punho e a deficiência. ${ }^{15}$

Devido à raridade da indicação cirúrgica, a maioria dos relatos que descrevem reconstruções do rádio distal após a ressecção do tumor ósseo incluem um número muito limitado de casos. Além disso, faltam informações sobre o resultado funcional dessas reconstruções.

No geral, não houve grandes complicações relacionadas ao implante, como infecção, não sindicalidade ou afrouxamento. Dois pacientes tiveram que se submeter a uma nova cirurgia para a prótese em protrusão, mas isso foi facilmente removido em um ambiente de cirurgia diária.

A função foi boa de acordo com os escores do MSTS e $\mathrm{DASH}$, e todos os pacientes voltaram à atividade diária normal sem grandes prejuízos. ${ }^{16}$

\section{Conclusão}

A maioria das opções de fusão de punho apresentadas na literatura após a ressecção do tumor envolve fusões biológicas, enquanto nossas fusões foram feitas usando uma prótese anatômica.

Nossos implantes, juntamente com um componente de ponte para a diáfise faltando/ressecado, funde o rádio ao carpo. O componente de artrodese carpometacarpal da nossa prótese aumenta a estabilidade e evita o afrouxamento dos componentes. Esse tipo de prótese beneficia-se do fato de que pode ser usada como opção de salvamento quando outros tratamentos falharam, ou pode ser usada como opção primária nos casos em que há estoque ósseo limitado após a ressecção do tumor do rádio distal. Esse tipo de reconstrução feita sob medida parece ser uma solução promissora em casos difíceis, porém é necessário um estudo mais aprofundado com maior grupo de estudo e maior acompanhamento.

\section{Conflito de Interesses}

Os autores não têm conflito de interesses a declarar.

O presente estudo foi realizado em conformidade com a Declaração da Associação Médica Mundial de Helsinque sobre Princípios Éticos para Pesquisa Médica Envolvendo Sujeitos Humanos, e foi revisado pelo Royal National Orthopaedic Hospital Institutional Review Board

\section{Referências}

1 Rabitsch K, Maurer-Ertl W, Pirker-Frühauf U, Lovse T, Windhager $\mathrm{R}$, Leithner A. Reconstruction of the Distal Radius following Tumour Resection Using an Osteoarticular Allograft. Sarcoma 2013;2013:318767

2 Amanatullah DF, Clark TR, Lopez MJ, Borys D, Tamurian RM. Giant cell tumor of bone. Orthopedics 2014;37(02):112-120

3 Yamamoto T, Akisue T, Marui T, Nagira K, Kurosaka M. Osteosarcoma of the distal radius treated by intraoperative extracorporeal irradiation. J Hand Surg Am 2002;27(01):160-164

4 Messerschmitt PJ, Garcia RM, Abdul-Karim FW, Greenfield EM, Getty PJ. Osteosarcoma. J Am Acad Orthop Surg 2009;17(08):515-527

5 Pollock R, Stalley P, Lee K, Pennington D. Free vascularized fibula grafts in limb-salvage surgery. J Reconstr Microsurg 2005;21(02):79-84

6 Bianchi G, Donati D, Staals EL, Mercuri M. Osteoarticular allograft reconstruction of the distal radius after bone tumour resection. J Hand Surg [Br] 2005;30(04):369-373

7 Maruthainar N, Zambakidis C, Harper G, Calder D, Cannon SR, Briggs TW. Functional outcome following excision of tumours of the distal radius and reconstruction by autologous non-vascularized osteoarticular fibula grafting. J Hand Surg [Br] 2002;27(02):171-174

8 Guedes A, Baptista PPR, Santili C, Yonamine ES, Garcia HRP, Martinez EC. Broad Resection and Fibular Transposition in the Treatment of GCT on Radius Distal End. Acta Ortop Bras 2009;17 (03):171-181

9 Hilven PH, Bayliss L, Cosker T, et al. The vascularised fibular graft for limb salvage after bone tumour surgery: a multicentre study. Bone Joint J 2015;97-B(06):853-861

10 Friedrich JB, Moran SL, Bishop AT, Wood CM, Shin AY. Free vascularized fibular graft salvage of complications of long-bone allograft after tumor reconstruction. J Bone Joint Surg Am 2008; 90(01):93-100

11 Minami A, Kato H, Iwasaki N. Vascularized fibular graft after excision of giant-cell tumor of the distal radius: wrist arthroplasty versus partial wrist arthrodesis. Plast Reconstr Surg 2002;110(01):112-117 
12 Murray JA, Schlafly B. Giant-cell tumors in the distal end of the radius. Treatment by resection and fibular autograft interpositional arthrodesis. J Bone Joint Surg Am 1986;68(05):687-694

13 Bowers WH. Distal radioulnar joint arthroplasty: the hemiresection-interposition technique. J Hand Surg Am 1985;10(02):169-178

14 Hayden RJ, Jebson PJ. Wrist arthrodesis. Hand Clin 2005;21(04): 631-640
15 De Smet L. Does restricted wrist motion influence the disability of the upper limb? Acta Orthop Belg 2007;73(04):446-450

16 Hudak PL, Amadio PC, Bombardier CThe Upper Extremity Collaborative Group (UECG). Development of an upper extremity outcome measure: the DASH (disabilities of the arm, shoulder and hand) [corrected]. Am J Ind Med 1996;29(06):602-608 